\title{
Brazil's Comparative Advantages and Specialization Dynamics in Agri-food Trade
}

Ivo Zdráhal ${ }^{1}$, Martin Hrabálek ${ }^{2}$, Petr $\mathrm{Kadlec}^{3}$, Oldřich Krpec ${ }^{4}$

${ }^{1}$ Department of Regional and Business Economy, Faculty of Regional Development and International Studies, Mendel University in Brno, Czech Republic

${ }^{2}$ Department of Territorial Studies, Faculty of Regional Development and International Studies, Mendel University in Brno, Czech Republic

${ }^{3}$ Department of Radio Electronics, Faculty of Electrical Engineering and Communication, Brno University of Technology, Czech Republic

${ }^{4}$ Department of International Relation and European Studies, Faculty of Social Studies, Masaryk University, Brno, Czech Republic

\begin{abstract}
In the last decades Brazil has become a global agri-food powerhouse. The article interrogates the shape and its stability of revealed comparative advantages in 46 of its agri-food products for the period 1995-2017. The results support the argument that the Brazil's agri-food trade was formed by comparative advantages of specific agri-food sectors. The results show that the external shape of agri-food specialization has strengthened, first since early 2000s and second when the trade shifted more towards China. The pattern was stable according revealed comparative (dis)advantage of particular products, more changes occurred in each product's score and in ranking of products. Products without initial comparative advantage seem to remain uncompetitive whilst the products with strong initial comparative advantage continue to be competitive. The persistence in distribution has increased. This suggests, the shape of Brazil's revealed comparative advantage in agri-food trade has evolved towards its finite structure (ceteris paribus).
\end{abstract}

\section{Keywords}

European Union, Liberalization, Markov Chain Model, MERCOSUR, Specialization.

Zdráhal, I., Hrabálek, M., Kadlec, P. and Krpec, O. (2021) "Brazil's Comparative Advantages and Specialization Dynamics in Agri-food Trade", AGRIS on-line Papers in Economics and Informatics, Vol. 13, No. 2, pp. 121-139. ISSN 1804-1930. DOI 10.7160/aol.2021.130210.

\section{Introduction}

Brazil is the most important country in Latin America as it is the most populous country and by far the largest economy in the region. Brazil has also the fastest growing agricultural sector in Latin America (Bojanic, 2017). From being a net-agricultural importer and food aid recipient as recently as the 1960s and 1970s, it has now become the world's third largest agricultural exporter. Brazil is the world's leading exporter of soybean (oilcakes and soybeans), sugarcane products (sugar and bioethanol), meat (beef and poultry), coffee and cereals and orange juice and is becoming serious competitor to the global market dominance of the world's leading agricultural exporters, the US and EU (Hopewell, 2016). These changes also stressed Brazil's position and importance regarding provision of global food security and environmental sustainability.

The successful story of Brazilian agriculture attracts attention and intense interest from its competitors as well as from other developing countries. As pointed by Pereira et al. (2012) and Martha et al. (2010), Brazil has transformed its agriculture into one of the most competitive tropical agriculture model in the world within the relative short period of one generation.

Brazil has a number of competitive advantages in agri-food production. These include a favorable climate that allows for two or more harvests per year, large extensions of cheap arable land, abundant supplies of water, varied soils and climates that encourage product diversity and technology/know-how of producers and agroindustries (EIU, 2010). As pointed by Hopewell (2016), Brazil's emergence as an agricultural 
powerhouse was the result not just of its natural factor endowments, but extensive intervention on the part of the Brazilian government which worked together with private sector. Also, Brazil has been able to attract a significant amount of foreign direct investment (Bojanic, 2017). Longterm investment in research and development, human capital, agricultural extension services and infrastructure were crucial and had the effect of constructing a new comparative advantage (Moreddu et al., 2017; Hubbard et al., 2017).

To put it more straight, the spectacular growth of Brazil's agricultural production in last two decades was caused mostly by following factors. Firstly, the agriculture sector could have built on profound modernization that happened between $60 \mathrm{~s}-90 \mathrm{~s}$ as a result of strong policies of the Brazilian state, aimed mostly at credit availability and incentives for farmers. Brazil's total factor productivity (TFP) for agriculture grew from a minuscule 0.17 percent annually in the early 1960 s to 3.15 percent in 2012 , what was one of the fastest TFP growth rates in the world (Maciel, 2018). In turn, TFP is one of the most crucial indicator of economic growth which causes preconditions for further economic development (Bilan etal., 2020). Second, macroeconomic stability after 1994 is often mentioned (Chaddad and Jank, 2006), together with the overall institutional stability (Mueller and Mueller, 2016). Third, Brazil invested vastly into the system of agricultural research - Empresa Brasileira de Pesquisa Agropecuária (EMBRAPA), thus providing necessary support to the innovations and its up-take within the sector (Martha et al., 2010; Mueller and Mueller, 2016). Fourth, overall cuts in tariffs levels helped Brazil to get market access and increase its integration in global agribusiness (Hopewell, 2016). Fifth, there were other exogenous factors in play, mostly rising prices on the world commodity markets that further enhanced investments in agriculture activities. The above findings reveal that the rise of Brazilian agriculture is a consequence of both developments of the Brazilian agricultural model and of exploitation of opportunities offered by more and more liberalized agrarian markets.

In the last decades, the ongoing economic globalization delivered incentives and changes in Brazil's overall production and trade structures. In the recent study, Nassif and Castilho (2020) concluded that Brazil's recent over-all trade pattern trajectory has been directed to a regressive pattern of specialization. By regressive specialization they refer to that in which both production and export structures are strongly oriented to primary and resource-based manufactured goods. Despite the significant increase of Brazilian trade flows, since the early-2000s the technological gaps of manufacturing sector have significantly increased. In other words, the international performance of Brazilian agribusiness became not just a matter of a specific segment of the economy; its development has significant implications for the entire external economic balance of Brazilian economy. As shown by Andrade (2017), the agribusiness sector became the most important part of foreign revenue for Brazil and the rising value of agricultural exports is offsetting the rising deficit in trade with manufactured products.

The fact that Brazil shows a comparative advantage (CA) and competitiveness in total agrarian foreign trade is quite obvious here. There is also a number of sectoral studies (e.g. Sterns and Spreen, 2010; Siqueira et al., 2011; Belova et al., 2012; Im and Hong, 2015; de Paula et al., 2018; Torok et al., 2018) investigating the CA of Brazil in its most exported agri-food products. To author's knowledge, surprisingly, there is no study that examines both the extent and the dynamics of specialization within the over-all segment of Brazil's agri-food trade. Our aim is thus to fill this gap.

Generally, the trade theories give dissimilar predictions regarding specialization dynamics of a country. According to the Heckscher-Ohlin model, the specialization pattern is formed based on countries relative endowment in production factors. The change in trade specialization can be expected only if there is change in relative endowment of the country, relative to its trading partners (Nazarczuk et al., 2018; Maciejewski, 2019). A certain limiting feature of this framework is that assumptions of the model do not have to be met by the economic realities.

Removing tariffs on goods traded between countries and reducing nontariff barriers by harmonizing product standards and simplifying government formalities reduces the transaction costs of trade which should lead to an increase in the degree of specialization (Aiginger, 2001; Ricci, A., 2018). Higher specialization can lead to higher productivity and competitiveness (and vice versa). Other streams of theoretical literature emphasize the endogeneity of technological change (Grossman and Helpman, 1991; Krugman, 1987; Lucas, 1988; Redding, 1999; Brodzicki, T. and Kwiatkowski, J., 2018) or economic geography that underlines the importance of agglomeration economies (Krugman, 1991; Fujita et al., 1999). particularly for developing countries like Brazil and others (Kostiukevych et al., 2020). Each of these streams of theoretical research identifies some forces that lead to persistence in trade patterns and other that stimulate mobility (Brodzicki, et al., 2018). The predictions offered by trade 
theories depend on assumptions which might be met. Empirical studies on agri-food production and trade (e.g., Milovanovic and Smutka, 2017; Hoang, 2019) suggest and support that changes in patterns and performance in trade are due to both demand and supply sides, both at domestic and international markets, both in factor-intensities and productivity differentials. Such changes are especially obvious when the world sugar market has been oscillating between surplus and deficit states (Smutka et al., 2020). Liberalization and integration are also channels for improvements in productivity, scale, and export expansion and a way to improve comparative advantage (Lisin et al., 2019). The above characteristics and context of Brazil's success as agriculture powerhouse points to the influence of factor endowment as well as endogenous and exogenous factors on the formation of Brazil's specialization in agri-food trade. It is the matter of empirical testing the shape of specialization, its evolution over time and the intra-distributional dynamics.

The presented paper interrogates evolution of the overall degree of specialization (the external shape) and the degree and the pattern of intradistributional mobility (changes in the intradistributional dynamics) within the Brazil's agrifood trade in the last almost 25 years.

The main contribution of this paper is that it takes a look at Brazilian agri-food sector over a longperiod of years 1995-2017. This approach gives the authors the possibility to cover different stages and also to concentrate on the competitiveness in a larger period than other studies. The time period analysed includes neoliberal policies (until 2002), the neo-developmentalism (2003-2016) and first years of political and economic crisis in Brazil (since 2015). Importantly, our analysis contributes to the conclusion, that neo-developmentalism - focused on promotion of complex industrial production (skill, knowledge, technology intensive) aiming on both domestic and world market (BresserPereira, 2009; Morais and Saad-Filho, 2012; Ban, 2013; Cypher, 2014) - did not succeed in Brazil and the dependence on agricultural exports altered during that period.

What's more, our data covering this long time period suggests, that the export success of agribusiness with strong and strengthening comparative advantage and competitiveness was not dependent only on Chinese and/or commodity boom (2000-2014). That is why our analysis presents more valid and also policy relevant understanding of contemporary development of Brazilian agri-food sector.

\section{Materials and methods}

To assess the shape of trade specialization and its stability, it is relevant to determine the country's comparative advantage in the products trade. The traditional approach is based on the concept of 'revealed' comparative advantage (RCA). Balassa (1965) developed the empirical method and it is widely used to identify a nation's most robust and weakest export sectors (Benešová et sl, 2018). The Balassa index (BI) compares the share of a product in a country's total export with the same share in the total World's exports. The BI index is mathematically presented as:

$$
B I_{i j}=\frac{\frac{x_{i j}}{x_{i}}}{\frac{x_{w j}}{x_{w}}}
$$

where $x$ indicates exports, i represents a nation, $j$ signifies a product and $w$ represents a set of countries. The BI is not symmetric; values between 0 and unity signify that the economy reveals comparative disadvantage (CdisA); values that exceed unity signify that the country is specialized in exporting the product and the country reveals CA in that given sector. The theoretical foundation and empirical distribution characteristics of the BI have been debated and criticized in the literature (Bowen, 1983; Vollrath, 1991; Hinloopen and Van Marrewijk, 2001; Sanidas and Sin, 2010; De Benedictis and Tamberi, 2004; Gnidchenko and Salnikov, 2015). Because of the shortcomings of the BI, other indices have been proposed (i.e. Bowen, 1983; Vollrath, 1991; Lafay, 1992; Dalum et al., 1998; Proudman and Redding, 2000; Hoen and Oosterhaven, 2006; Yu et al., 2009; Leromain and Orefice, 2014). At this point, it is worth emphasizing, that none of alternatives seems to be without problems and the common practice in trade studies is to use more indices to see if there is a glaring difference.

In contrast to BI, the Lafay Index (LFI) uses both imports and exports. The LFI norms the trade balance of individual products with the overall balance and weights it in the trade structure. The LFI allows control of intra-industry trade and re-exporting flows, is symmetric and seems to be more reliable than the $\mathrm{BI}$ when comparing the values in time series. The LFI is defined as (Lafay, 1992; Zaghini, 2003):

$$
\operatorname{LFI}_{j}^{i}=100\left(\frac{x_{j}^{i}-m_{j}^{i}}{x_{j}^{i}+m_{j}^{i}}-\frac{\sum_{j=1}^{N}\left(x_{j}^{i}-m_{j}^{i}\right)}{\sum_{j=1}^{N}\left(x_{j}^{i}+m_{j}^{i}\right)}\right) \frac{x_{j}^{i}+m_{j}^{i}}{\sum_{i=j}^{N}\left(x_{j}^{i}+m_{i}^{i}\right)},
$$

where $x$ and $m$ represent the export and import values of every product group. Zero signifies 
a comparative advantage neutral point. LFI's positive value indicates the existence of CA for a particular sector and a negative value signifies the presence of a CdisA. The higher index value indicates a higher degree of CA and specialization and vice versa.

The Normalized revealed comparative advantage index (NI) was proposed by $\mathrm{Yu}$ et al. (2008) as another alternative measure of RCA. Due to the fact that it is comparable across products, countries and time, the index should more precisely and consistently reveal the extent of CA that a country has in a certain product, making it another useful quantitative tool.

$$
N I=\frac{x_{i j}}{x_{w}}-\frac{x_{j} \times x_{w j}}{x_{w} \times x_{w}}
$$

The NI index ranges from -0.25 to 0.25 and the comparative neutral point is zero. The sum (and the mean value) of scores is constant and equals to zero and a sum of positive scores equals the sum of negative scores. If NI is higher (lower) that 0 , country reveal comparative advantage (disadvantage) in product $i$. The higher the value, the stronger CA and vice versa.

Statistical data were obtained from databases of the UNCTAD, for the period between 1995 and 2017. The commodity structure of individual sectors (products) in agri-food trade is defined according to the SITC (revision 3). The analysis is done at the level of 3-digit code for 46 various agri-food products traded (SITC $0+1+22+4$ ). The values of BI, LFI and NI have been calculated for each agri-food product groups (table A1 in Annex) traded between Brazil and World market for the period from 1995 through 2017.
The descriptive statistics of pooled data is presented in following table (Table 1).

Scores of BI, LFI and NI were analyzed regarding its consistency. Ballance et al. (1987) suggest empirical tests to examine the extent to which various RCA indices are consistent as a cardinal measure (the extent to which a country has a $\mathrm{CA} / \mathrm{Cdis} \mathrm{A}$ in a product), ordinal measure (consistent in ranking product groups by RCA) and dichotomous measure (similarity in suggesting whether the product group have CA or CdisA).

Also, scores of BI, LFI and NI were examined regarding how weak or strong the comparative advantage of each product is. Following Hinloopen and Van Marrewijk (2001), BI scores were grouped using absolute thresholds: reveal CdisA $(\mathrm{BI} \leq 1)$, weak $\mathrm{CA}(\mathrm{BI}>1$ and $\mathrm{BI} \leq 2)$, medium $\mathrm{CA}(\mathrm{BI}>2$ and $\mathrm{BI} \leq 4)$ and strong $\mathrm{CA}(\mathrm{BI}>4)$. There is no general guidance in literature for classifying the LFI and NI values into classes, so the data was grouped based on quartiles (relative thresholds) from positive LFI values: reveal CdisA (LFI $\leq 0)$, weak $\mathrm{CA}(\mathrm{LFI}>0$ and $\mathrm{LFI} \leq 0.032$; first and second quartile), medium CA (LFI $>0.032$ and $\mathrm{LFI} \leq 0.293$; third quartile) and strong CA (LFI $>0.293$; fourth quartile); and positive NI values: reveal CdisA $(\mathrm{NI} \leq 0)$, weak $\mathrm{CA}(\mathrm{NI}>0$ and $\mathrm{NI} \leq 17.70$; first and second quartile), medium $\mathrm{CA}(\mathrm{NI}>17.70$ and $\mathrm{NI} \leq 32.31$; third quartile) and strong CA (LFI $>32.31$; fourth quartile).

First, a static view on the comparative advantage of individual products is applied using mean values (1995-2017) of BI, LFI and NI to assess and to identify the agri-food products revealing CA or CdisA and so the capacity to cope with competitive pressures of the world.

\begin{tabular}{|l|c|c|c|}
\hline & BI & LFI & NI \\
\hline Theoretical range & $0 \leq \mathrm{BI} \leq+\infty$ & $-\infty \leq \mathrm{LFI} \leq+\infty$ & $-2,500 \leq \mathrm{NI} \leq+2,500$ \\
\hline CANP & 1 & 0 & 0 \\
\hline Min & 0.000 & -9.604 & -33.834 \\
\hline Max & 7.215 & 8.170 & 144.695 \\
\hline Range & 7.215 & 17.774 & 178.529 \\
\hline Mean & 0.849 & 0.000 & 0.000 \\
\hline s.d. & 1.448 & 1.621 & 19.083 \\
\hline Median & 0.146 & -0.064 & -2.393 \\
\hline Skewness & 2.073 & 0.235 & 2.842 \\
\hline Kurtosis & 3.445 & 7.759 & 12.977 \\
\hline
\end{tabular}

Note: CANP - Comparative advantage neutral point; following Yu et al. (2009), the scores are rescaled by multiplying 10,000 without affecting the results. Source: Own calculation based on UNCTAD (2019)

Table 1: Descriptive statistics of pool data (Balassa, Lafay and Normalized indices; 1995-2017). 
Following the recent empirical studies in agri-food trade (Hinloopen and Van Marrewijk, 2001; Ferto and Hubbard, 2003; Kostoska and Hristoski, 2018; Hoang, 2019), a battery of empirical approaches is employed to analyze structural stability of the Brazil's agri-food comparative advantage. According to Hinloopen and Van Marrewijk (2001), one can distinguish at least two types of stability; first, the stability of the distribution of the indices from one period to the next (Stability I); second, the stability of the value of the indices for particular product groups from one period to the next (Stability II).

\section{Stability I}

Based on procedures suggested by Hinloopen and Van Marrewijk (2001), summary statistics can be employed to investigate the external shape of the distribution of RCA indices. Also, following Ferto and Hubbard (2003), the correlation between the indices in time period $t$ and the index in subsequent time periods was employed as the indicator of structural stability of Brazil's agri-food trade pattern. Another indicator of stability is the relative importance (in the export structure) of products that reveal CA in the period $\mathrm{t}$, but reveal CdisA in the period $\mathrm{t}+1$ or viceversa (Kostoska and Hristoski 2018). Because the year-by-year fluctuation, the comparison is made between average value of indices at the beginning (avg.1995-1999) and at the end (2013-2017) of the observed period.

\section{Stability II}

To assess the structural changes in the over-all as well as at the sectoral level, the stability is analyzed in term of the RCA scores's distribution of specific products in mentioned 4 classes (CdisA, weak, medium and strong $\mathrm{CA}$ ) from one period to the next. Following Quah (1996), Proudman and Redding (2000), Brasili et al. (2000), Hinloopen and Van Marrewijk (2001) and Zaghini (2005), the changes in distribution of products among the particular classes were analyzed using Markov chain model. The evolution of RCA distribution over time may be modeled formally to measure the probability that a product group moves from one class to another. Thus represent the RCA by the measure $\mathrm{x}$ and its distribution across sectors at time $t$ by $F_{t}(x)$. Corresponding to $F_{t}$, it can be define a probability measure $\lambda_{t}$, where $\lambda_{t}\left(\left(\lambda_{t-1}, x\right)\right)=F_{t}(x)$. The evolution of the distribution of RCA over time is then modeled in terms of a stochastic difference equation:

$$
\lambda_{t}=\mathbf{P}\left(\lambda_{t-1}, \mathbf{u}_{t}\right)
$$

where $u_{t}$ is the error term and $P$ is an operator which measures if an element, initially part of distribution $F_{t-1}$, will end in $F_{t}$. If the operator $P$ is time invariant and the disturbances are equal to zero, by iterating the relation above, could be obtain:

$$
\lambda_{\mathbf{t}+\mathrm{s}}=\mathbf{P} \times \boldsymbol{\lambda}_{\mathbf{t}+\mathrm{s}-1}=\cdots=\mathbf{P}^{\mathrm{s}} \times \boldsymbol{\lambda}_{\mathbf{t}}
$$

Allocating the RCA into the classes, the operator $P$ becomes a transition matrix. An element of it, $p_{i j}$, represents the probability that a value, which at the beginning of the period was in the state $i$, will be, after s years, in state ${ }_{j}$. If the larges values are situated on the main diagonal of the transition matrix, then the mobility inside the distribution is rather small and vice versa.

The general degree of mobility can be assessed using trace and the determinant of transition matrix, as follows:

$\mathbf{M}_{\mathbf{1}}=\frac{\mathbf{n}-\operatorname{tr}(\mathbf{P})}{\mathbf{n}-\mathbf{1}}$, respectively $\mathbf{M}_{2}=\mathbf{1}-|\operatorname{det}(\mathbf{P})|$,

$n$ is the number of classes; $\operatorname{tr}(P)$ is the trace of matrix $P$; $\operatorname{det}(P)$ is the determinant of matrix $P$. $M_{1}$ captures the importance of diagonal and off-diagonal terms. In the case of total persistence, the value of $M_{1}$ would be zero. In the case of total mobility, the $M_{1}$ would be 1 . The $M_{2}$ gives similar explanation. When the values on the main diagonal are close to 1 and those on the off-diagonal small (high persistence), the matrix determinant takes a value close to 1 and the mobility indicator is 0 . The assessment of persistence resp. mobility was done over the entire reporting period. Furthermore, the year-on-year M1 and M2 indices were calculated to assess its changes from 1995 to 2017. This allows to evaluate, whether distribution of product among product's classes is already formed or is still undergoing changes.

\section{Results and discussion}

\section{Brazil's agri-food trade dynamic}

Brazil's total agri-food export value increased 5.9 times between 1995 and 2017 to 77,612 million USD. The value of total agri-food import to Brazil rose 1.7 times and reached 9,929 million USD in 2017. The share of agri food trade in the total foreign trade of Brazil has been around $20 \%$ and has slightly increased to $22.5 \%$ in 2017 . The agri-food export still generates around $70 \%$ share on total foreign export, despite a slight decrease in the last decade $(65.1 \%$ in 2017). Contrary, the agri food import generates only around $5 \%$ on total import. The trade balance 
index (TBI) confirms the increasing position of Brazil as a net-exporter of agri food products. Agri-food represents a significant and positive contribution to Brazil's trade balance $(+73$ billion USD in 2017). The figure 1 (Fig. 1) shows the change in Brazil's agri food trade between 1995 and 2017.

The dynamics of agri-food trade varied during the reviewed period. In the early 2000 s agri-food exports saw a significant increase, when the implementation of Uruguay Round Agreement on Agriculture was completed. Together with decrease in unilaterally applied tariffs levels and preferential applied tariffs levels Brazil got market access and increased its integration in global agribusiness. Likewise, the overall rise in commodity prices (especially in the period before the Great Recession during the late 2000s and early 2010s) contributed to an increase in the value of the Brazilian agricultural exports. Brazil mainly exports soybean (oilcakes and soybeans), sugar, beef and poultry, coffee, tobacco, maize and orange juice.

Regarding the territorial structure, the regional integration within MERCOSUR has not stimulated the intensity of agri-food trade between Brazil and other MERCOSUR countries. On the other hand, the structure of extra-regional trade has changed significantly. The value of agri-food trade between Brazil and the EU28 has increased. However, the European Union is gradually losing its position as Brazil's most important agri-food trading partner. In the same time, China's position as a trading partner for agri-food products has increased in a large manner during the period of the Chinese commodity boom (2000-2014) and especially in the period after Great Recession.

The dynamics could be a bit changed if the ambitious and comprehensive trade agreement between the European Union and MERCOSUR was finalized. At the moment of finishing this article, a political agreement was found. The way to put the deal into practice will be difficult though, due to the fact that there is a strong resistance from some of the member states of the EU, based mainly on agricultural arguments. Concerning the changes in the commodity structure of the production and agrarian trade in the Central and Eastern European countries (Svatoš and Smutka, 2010; Maitah et al., 2016), meat and sugar exports coming from Brazil may further form changes in these sectors. More detailed summary of changes in Brazil's export and import and territorial structures of agri-food trade can be found in Zdráhal et al (2019).

\section{Measuring Brazil's revealed comparative advantages in agri-food products}

The revealed comparative advantage of 46 sectors of agri-food trade of the Brazil was evaluated using the BI, LFI and NI indices. The consistency of BI, LFI and NI was examined (Table 2) using tests suggested by Ballance et al. (1987).

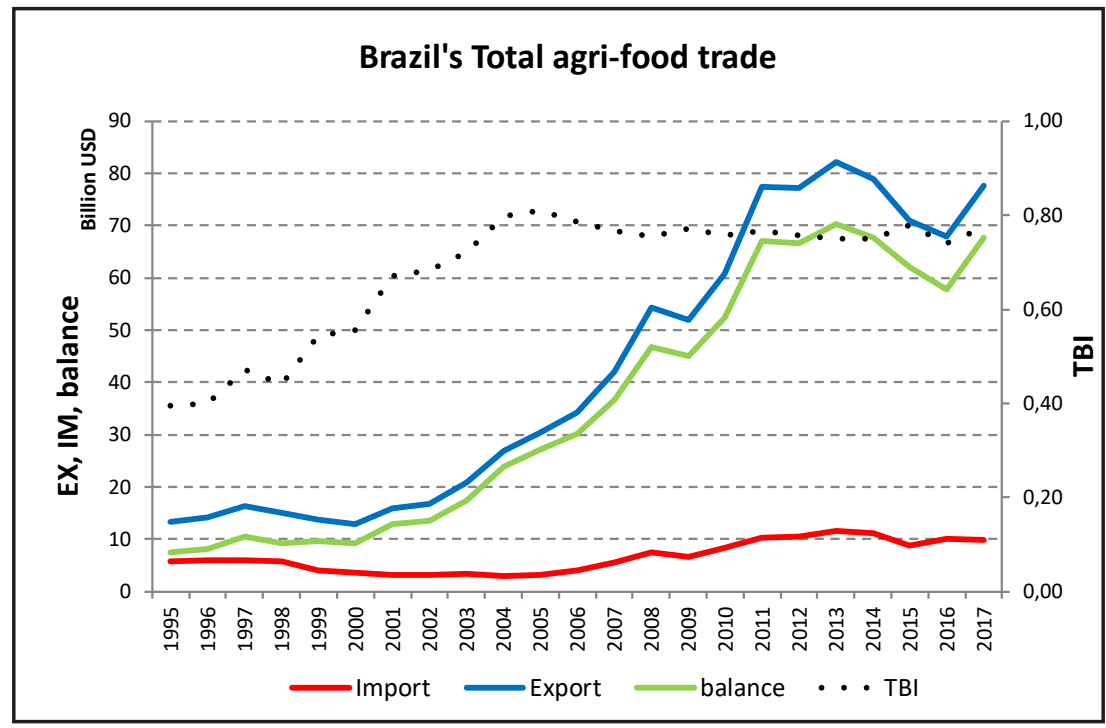

Note: Trade balance index (TBI) compares the balance of trade (X-M) to its turnover $(\mathrm{X}+\mathrm{M})$; the value close to 1 would mean that the country only exports

Source: Authors' calculations based on UNCTAD data (SITC, 3-digit level)

Figure 1: Change in Brazil's agri food trade (export, import, balance and trade balance index), 1995-2017. 


\begin{tabular}{|l|l|l|l|l|l|l|l|l|l|}
\hline & & & $\mathbf{1 9 9 5}$ & $\mathbf{2 0 0 0}$ & $\mathbf{2 0 0 5}$ & $\mathbf{2 0 1 0}$ & $\mathbf{2 0 1 5}$ & $\mathbf{2 0 1 7}$ & avg. \\
\hline \multirow{3}{*}{ BI } & \multirow{3}{*}{ LFI } & Cardinal & 0.725 & 0.730 & 0.751 & 0.789 & 0.823 & 0.848 & 0.752 \\
\cline { 3 - 10 } & Ordinal & 0.548 & 0.727 & 0.622 & 0.694 & 0.624 & 0.663 & 0.684 \\
\cline { 3 - 10 } & & Dichotomous & 0.826 & 0.826 & 0.935 & 0.913 & 0.935 & 0.957 & 0.879 \\
\cline { 3 - 10 } & \multirow{3}{*}{ NI } & Cardinal & 0.870 & 0.890 & 0.876 & 0.877 & 0.866 & 0.879 & 0.873 \\
\cline { 3 - 10 } & Ordinal & 0.657 & 0.680 & 0.635 & 0.643 & 0.650 & 0.656 & 0.656 \\
\cline { 3 - 10 } & & Dichotomous & 1.000 & 1.000 & 1.000 & 1.000 & 1.000 & 1.000 & 1.000 \\
\hline \multirow{3}{*}{ LFI } & \multirow{3}{*}{ NI } & Cardinal & 0.827 & 0.798 & 0.848 & 0.900 & 0.940 & 0.953 & 0.855 \\
\cline { 3 - 10 } & & Ordinal & 0.838 & 0.748 & 0.793 & 0.841 & 0.860 & 0.865 & 0.831 \\
\cline { 3 - 10 } & & Dichotomous & 0.826 & 0.826 & 0.935 & 0.913 & 0.935 & 0.957 & 0.879 \\
\hline
\end{tabular}

Source: Authors' calculations based on UNCTAD data (SITC, 3-digit level)

Table 2: Tests of consistency - correlation coefficients of paired RCAs indices.

The consistency test of the indices as cardinal measures of comparative advantage was based on the correlation coefficient between paired indices in each of the 23 years. The BI, LFI and NI show a high level of correlation ( $\geq 0.75)$, especially the $\mathrm{BI} \leftrightarrow \mathrm{NI}$ and LFI $\leftrightarrow \mathrm{NI}$ pairs. This suggests that the indices are consistent as cardinal measures. The consistency test of the indices as ordinal measures (cross-sector ranking) was based on the rank correlation coefficient for each pairing. On average, the BI $\leftrightarrow$ LFI and $\mathrm{BI} \leftrightarrow \mathrm{NI}$ pairs show moderate level of correlation and LFI $\leftrightarrow$ NI pair shows high level of correlation.

Results show that the LFI and NI indices are consistent in ranking product groups by revealed comparative advantage. On the other hand, LFI and NI indices give slightly different rankings in comparison to BI indices. The test of indices as a dichotomous measure was based on assessment of the share of product groups in which both of the paired indices suggest CA or CdisA. This test indicates that $\mathrm{BI}$ and $\mathrm{NI}$ have perfect match in the all years under analysis. The BI $\leftrightarrow$ LFI and LFI $\leftrightarrow \mathrm{NI}$ pairs are also highly consistent with all the year-by-year shares higher than $70 \%$ ( $87.9 \%$ on average).

This indicates that BI, LFI and NI used in the analysis give very similar results (same results in the case of BI and NI) whether or not Brazil has a comparative advantage in a given agri-food sector and how many sectors are considered to have a CA according to each RCA index. Also, BI, LFI and NI should give similar results, when examining how much more of CA a given agri-food sector in Brazil has in comparison to other agri-food sectors in Brazil and how much has the sector gained through time. On the other hand, only moderately similar results (except of LFI $\leftrightarrow \mathrm{NI}$ ) can be expected when ranking the Brazil's agri-food sectors according revealed CA or CdisA. This result gives support to the findings on consistency of BI, LFI and NI in studies of Sanidas and Shin (2010) and Hoang (2019).

As anticipated by the consistency tests of dichotomous and cardinal characteristics, the statistical findings (mean) for BI and NI (Table 3) exhibit similar patterns and both of them point, on average from 1995 to 2017, to a revealed CA for 12 products: 011 (reveals weak CA); 012 (medium/strong); 016 (weak); 017 (weak); 044 (weak); 059 (weak/medium); 061 (strong); 071 (medium/strong); 081 (medium/strong); 121 (medium); 222 (strong); 421 (CdisA/weak). The Lafay index takes into consideration also imports and it also eliminates various other factors (Zaghini, 2005) and points to a revealed CA also for 5 other products. But scores of 3 (listed here in SITC codes: 047, 074, 075) out of that 5 are close to comparative advantage neutral point (zero). The other two are: 036 (weak) and 122 (weak). Also, the LFI is revealing (although small) comparative disadvantage in a case of 421, contrariwise to BI and NI (Table 3).

As indicated by the consistency test of ordinal characteristics, the average RCA scores do not always match each other when ranking the products. However, the most competitive product groups of Brazil's agri-food trade are 222, 061 and 071. The cross sectoral comparison and revealed CA or CdisA of specific products is in line with general perception of Brazil as the world's leading exporter of soybean (oilcakes and soybeans; codes 222, 081), sugarcane products (sugar; 061), coffee (071), meat (beef and poultry; 011-017), cereals (044) and orange juice (059). Average RCA's scores do not match when ranking the milk based products $(022,024)$, fish $(034,035,037)$, cereals and cereals based products $(041,042,043$, 


\begin{tabular}{|c|c|c|c|c|c|c|c|c|c|c|c|c|c|}
\hline \multirow{2}{*}{ SITC } & \multicolumn{2}{|c|}{ BI } & \multicolumn{2}{|c|}{ LFI } & \multicolumn{2}{|c|}{ NI } & \multirow{2}{*}{ SITC } & \multicolumn{2}{|c|}{ BI } & \multicolumn{2}{|c|}{ LFI } & \multicolumn{2}{|c|}{ NI } \\
\hline & avg. & rank & avg. & rank & avg. & rank. & & avg. & rank & avg. & rank & avg. & rank \\
\hline 001 & 0.24 & 21. & -0.10 & 25. & -5.84 & 29. & 057 & 0.27 & 18. & -1.13 & 40. & -21.71 & 45. \\
\hline 011 & 1.77 & 8. & 0.59 & 9. & 11.78 & 8. & 058 & 0.12 & 28. & -0.16 & 29. & -5.58 & 28. \\
\hline 012 & 2.04 & 7. & 2.49 & 4. & 25.58 & 4. & 059 & 3.85 & 5. & 1.46 & 6. & 14.89 & 7. \\
\hline 016 & 1.07 & 12. & 0.07 & 12. & 0.37 & 12. & 061 & 4.89 & 1. & 3.38 & 2. & 48.90 & 2. \\
\hline 017 & 1.68 & 9. & 0.60 & 8. & 4.17 & 10. & 062 & 0.46 & 16. & -0.04 & 20. & -2.17 & 23. \\
\hline 022 & 0.07 & 32. & -1.32 & 42. & -12.94 & 40. & 071 & 4.00 & 4. & 3.02 & 3. & 32.62 & 3. \\
\hline 023 & 0.02 & 41. & -0.07 & 22. & -2.66 & 26. & 072 & 0.48 & 14. & -0.25 & 32. & -3.56 & 27. \\
\hline 024 & 0.01 & 44. & -0.31 & 33. & -10.10 & 36. & 073 & 0.17 & 25. & -0.23 & 31. & -6.67 & 32. \\
\hline 025 & 0.26 & 20. & -0.03 & 19. & -1.23 & 17. & 074 & 0.26 & 19. & 0.01 & 15. & -2.11 & 22. \\
\hline 034 & 0.06 & 35. & -1.37 & 43. & -18.81 & 43. & 075 & 0.79 & 13. & 0.01 & 14. & -0.64 & 14. \\
\hline 035 & 0.03 & 39. & -0.82 & 37. & -2.10 & 21. & 081 & 2.22 & 6. & 2.49 & 5. & 23.25 & 5. \\
\hline 036 & 0.17 & 24. & 0.12 & 11. & -10.19 & 37. & 091 & 0.13 & 27. & -0.06 & 21. & -1.59 & 19. \\
\hline 037 & 0.03 & 40. & -0.15 & 28. & -8.59 & 33. & 098 & 0.21 & 22. & -0.67 & 36. & -16.50 & 42. \\
\hline 041 & 0.07 & 31. & -4.83 & 46. & -12.92 & 39. & 111 & 0.06 & 34. & -0.09 & 24. & -6.15 & 31. \\
\hline 042 & 0.15 & 26. & -1.21 & 41. & -5.94 & 30. & 112 & 0.04 & 38. & -0.99 & 39. & -25.66 & 46. \\
\hline 043 & 0.01 & 46. & -0.22 & 30. & -2.40 & 25. & 121 & 4.51 & 3. & 1.21 & 7. & 16.12 & 6. \\
\hline 044 & 1.31 & 11. & 0.05 & 13. & 5.08 & 9. & 122 & 0.19 & 23. & 0.23 & 10. & -9.85 & 35. \\
\hline 045 & 0.06 & 33. & -0.10 & 26. & -1.17 & 16. & 222 & 4.79 & 2. & 3.96 & 1. & 71.99 & 1. \\
\hline 046 & 0.01 & 45. & -0.38 & 34. & -1.84 & 20. & 223 & 0.02 & 43. & -0.02 & 17. & -0.94 & 15. \\
\hline 047 & 0.38 & 17. & 0.01 & 16. & -0.26 & 13. & 411 & 0.11 & 29. & $\begin{array}{l}-0.07 \\
\end{array}$ & 23. & -1.56 & 18. \\
\hline 048 & 0.07 & 30. & -2.00 & 45. & -14.09 & 41. & 421 & 1.46 & 10. & -0.02 & 18. & 3.90 & 11. \\
\hline 054 & 0.02 & 42. & -1.47 & 44. & -20.23 & 44. & 422 & 0.05 & 36. & -0.52 & 35. & -10.75 & 38. \\
\hline 056 & 0.04 & 37. & -0.95 & 38. & -9.55 & 34. & 431 & 0.47 & 15. & -0.11 & 27. & -2.35 & 24. \\
\hline $\mathbf{B I} / \mathbf{N I}$ & 1995 & 2000 & 2005 & 2010 & 2015 & 2017 & LFI & 1995 & 2000 & 2005 & 2010 & 2015 & 2017 \\
\hline NCA & 10 & 11 & 10 & 11 & 11 & 11 & $\mathrm{CA}$ & 18 & 17 & 13 & 15 & 14 & 13 \\
\hline NCdA & 36 & 35 & 36 & 35 & 35 & 35 & NCdA & 28 & 29 & 33 & 31 & 32 & 33 \\
\hline
\end{tabular}

Note: Green - strong CA, blue - medium CA, yellow - weak CA; NCA - Number of sectors revealing comparative advantage; NCdA number of sectors revealing comparative disadvantage; $\mathrm{BI}$ and NI revealed CA or CdisA for the same products (see dichotomous test of $\mathrm{BI}$ and $\mathrm{NI}$ )

Source: Authors' calculations based on UNCTAD data (SITC, 3-digit level)

Table 3: Mean and ranking of specific sectors according to BI, LFI and NI values, Brazil.

046, 048), vegetables $(054,056)$, fruits and nuts (057), edible products and preparations (098) and alcoholic beverages (112).

There is also a link between RCA's scores and the shares of specific products in export and import structures. Products revealing CA are generally the export sectors of Brazil's agrarian and food sectors and account, on average, for $89.8 \%$, $91.5 \%$ and $89.8 \%$ of total agri-food exports using BI, LFI and NI index. Products revealing CdisA are the import sectors and account, on average, for $87.1 \%, 87.2 \%$ resp. $87.1 \%$ of agri-food imports. The share of products revealing CA resp. CdisA on Brazil's agri-food export resp. import has increased from 1995 to 2017. This would seem to support the argument that the Brazil's agri-food trade has formed by following comparative advantage of specific agri-food sectors.
The results presented in the prior text show the Brazil's agri-food trade comparative advantages distribution in relation to all trade partners. As pointed by Smutka et al. (2018), certain weakness of such an analyses could be the fact that the above mentioned calculations do not take into consideration existing the differences among the individual countries (or groups of countries) and the trade policies.

The LFI index (which is suitable for analyses on the bilateral level) was used to interrogate the existence of differences in distribution of comparative advantages in relation to main agri-food trading partners of Brazil. The results (table A3 in Annex) indicate that such differences currently do exist. Brazil reveals more comparative advantage trading with other MERCOSUR countries and the Latin America and the Caribbean 
when compare to EU28, USA, China or rest of the World (excl. the previous mentioned). With respect to specific product groups, some (e.g., sugars, 061; unmanufactured tobacco, 121) reveal $\mathrm{CA}$ with all territories. Others show existence of differences revealing $\mathrm{CA}$ and/or CdisA with specific trading partners. This would support the argument that differences in conditions for agriculture production as well as the degree of protectionism and set-ups of trading regimens are affecting the distribution of revealed comparative advantages in relation to main agri-food trading partners of Brazil.

\section{Stability I (external shape of the distribution of RCA)}

The number of products revealing CA has slightly changed and high coefficients of variation of some agri-food products (not presented here) indicate dispersion in the variables between 1995 and 2017. This could signal a relative instability of some RCA indices and possible ongoing structural change of Brazil's agri-food trade pattern. The summary statistics (mean, median, range, skewness i.e.; see table A3 in Annex) of the BI, LFI and NI were further investigated to assess the evolution of the external shape of the distribution of RCA and thus the overall degree of specialization.

Because $\mathrm{BI}$ is not symmetrical, the minimum values are very close to 0 . The maximum values decreased between 1995 and 2001 and later fluctuated between 5.00 and 6.00 (but there is growing tendency in the last 5 years). The mean value of BI increased between 1995 and 2001 and started to decrease later. A probably better indication of central tendency is the median. The median values show slight increase between 1995 and 2007 and decrease in the later period. The kurtosis and skewness show same tendency. The skewness has the tail on the right and the distribution shifts to the left. This is signaling higher proportion of low values.

The LFI signals steadily increase in minimum values (from -9.60 to -2.30 ). The maximum values were decreasing till around 2005 and are increasing since that. The range dropped between 1995 and 2005 and started to slightly increase (standard deviation shows same tendency). The mean value of LFI is always zero. The median values first improved (from -0.20 in 1995 to -0.04 in 2001), but then started to decrease $(-0.10$ in 2017). The skewness first tended to the right (negative values), but then tended to the left (positive values) with the tail on the right. This signals higher proportion of low values as the skewness (positive) value is steadily increasing.

The NI signals steady decrease (increase) of minimum resp. maximum values and thus increasing gap between the loosing and flagship products. There is no change in trend as in the case of BI and LFI. This may be caused by properties of the NI index, because if country gains CA in some commodities, the NI deteriorates the scores in some other commodities ( $\mathrm{Yu}$ et al., 2009). The median values show steady decrease since 1998. The skewness has the tail on the right. First (1995-2007), the distribution slightly shifted to the right but later (2007-2017) it significantly shifted to the left. This signals higher proportion of low values.

These results indicate certain weakening in Brazil's overall degree of agri-food specialization at the beginning of the analyzed period, followed by specialization tendency since beginning of 2000's when Brazil's agri-food export started to grow very rapidly. Thus, the boom of Brazil's soya (S222) production and its export to China significantly increased the degree of Brazil's specialization in the period after the Great Recession.

Following Ferto and Hubbard (2002), as indicator of structural stability of Brazil's agri-food trade pattern, the correlation between the indices in time period $t$ and the index in subsequent time periods was employed. The test (table 4) shows similarity or difference in selected years relative to 1995 . The test also examine to what extent each BI, LFI and NI are time-consistent in its cardinal, ordinal and dichotomous characteristics during the observed period (Table 4).

The results suggest that the change from the initial status was rather in cardinal and ordinal characteristics than in dichotomous one. In other worlds, products without CA in 1995 seem to rather remain to be uncompetitive. Similarly, the products with CA in 1995 rather continue to maintain its competitive position. However, partial changes have occurred. The BI, LFI and NI changed significantly according its cardinal and ordinal characteristics from 1995 to 2017. This supports the conclusion, that structure of Brazil's agri-food trade pattern is rather stable (according what product groups reveal CA or CdisA), much significant changes occurred in each product RCA score (how much CA) and in ranking of product groups.

From 1995 to 2017 , according to BI and NI scores, 8 products $(012 ; 017 ; 059 ; 061 ; 071 ; 081 ; 121 ; 222)$ were exhibiting the CA in every year; 3 products $(011 ; 016 ; 044)$ status has improved and gain CA; 2 products status deteriorated $(075 ; 421)$ and started to reveal CdiA. The LFI scores give the same conclusion. Also, LFI scores indicate more 


\begin{tabular}{|c|l|c|c|c|c|c|c|}
\hline & & $\mathbf{9 5 - 0 0}$ & $\mathbf{9 5 - 0 5}$ & $\mathbf{9 5 - 1 0}$ & $\mathbf{9 5 - 1 5}$ & $\mathbf{9 5 - 1 7}$ & avg. \\
\hline \multirow{3}{*}{ BI } & Cardinal & 0.929 & 0.817 & 0.753 & 0.667 & 0.635 & 0.809 \\
\cline { 2 - 8 } & Ordinal & 0.941 & 0.827 & 0.707 & 0.667 & 0.684 & 0.786 \\
\cline { 2 - 8 } & Dichotomous & 0.978 & 0.957 & 0.891 & 0.891 & 0.891 & 0.933 \\
\hline \multirow{2}{*}{ LFI } & Cardinal & 0.644 & 0.613 & 0.601 & 0.479 & 0.454 & 0.589 \\
\cline { 2 - 8 } & Ordinal & 0.811 & 0.773 & 0.687 & 0.674 & 0.657 & 0.753 \\
\cline { 2 - 8 } & Dichotomous & 0.891 & 0.804 & 0.761 & 0.783 & 0.761 & 0.835 \\
\hline \multirow{2}{*}{ NI } & Cardinal & 0.863 & 0.731 & 0.710 & 0.532 & 0.493 & 0.728 \\
\cline { 2 - 8 } & Ordinal & 0.931 & 0.902 & 0.825 & 0.806 & 0.797 & 0.872 \\
\cline { 2 - 8 } & Dichotomous & 0.978 & 0.957 & 0.891 & 0.891 & 0.891 & 0.933 \\
\hline
\end{tabular}

Source: Authors' calculations based on UNCTAD data (SITC, 3-digit level)

Table 4: Stability of revealed comparative advantage - the correlation in time.

changes. The product group Other cereal meal, flours (047) was maintaining weak CA (exc. 1997), product group Live animals $(001)$ gain weak CA, and some product groups $(036 ; 072 ; 074 ; 075 ; 091$; 431) started to reveal comparative disadvantage. More significant changes indicated by LFI are consistent with (dichotomous) stability test of indices. The correlation coefficient decreased more in the case of LFI (0.761) than BI and NI (0.933).

Another indicator of (un)stability is the relative importance of products (in the export and import flows) that reveal a CA in the period t, but a CdisA in the period $t+1$ (Table 5) or vice-versa (Ballance et al., 1987).

\begin{tabular}{|l|c|c|c|c|c|c|}
\hline \multirow{2}{*}{} & & RCAt & RCDt+1 & & RCDt & RCAt+1 \\
\cline { 3 - 4 } \cline { 6 - 7 } & & $\mathbf{1 9 9 5}$ & $\mathbf{2 0 1 7}$ & & $\mathbf{1 9 9 5}$ & $\mathbf{2 0 1 7}$ \\
\cline { 2 - 7 } & No. & $\mathbf{\%}$ & $\mathbf{\%}$ & No. & $\mathbf{\%}$ & $\mathbf{\%}$ \\
\hline BI/NI & 2 & 8.67 & 1.86 & 3 & 1.44 & 12.96 \\
\hline LFI & 8 & 14.90 & 2.66 & 3 & 1.44 & 12.96 \\
\hline
\end{tabular}

Source: Authors' calculations based on UNCTAD data (SITC, 3-digit level)

Table 5: Stability of revealed comparative advantage - relative importance of products.

Those product groups that revealed CA in 1995 but CdisA in 2017 (BI and NI: 075, 421; LFI: 036, 072, 074, 075, 091, 122, 421, 431) accounted for $8.67 \%$ (BI and NI) and $14.90 \%$ (LFI) of the total agri-food export in 1995 resp. 1.86\% (BI and NI) and $2.66 \%$ (LFI) in 2017. The products showing opposite (revealing CdisA in 1995 and CA in 2017) movement (BI and NI: 011, 016, 044; LFI: 001, 011,044 ) change from $1.44 \%$ to $12.96 \%$ of the total agri-food export. Although the values are similar (rounding effect), BI and NI marked different product than LFI in one case.

Results of this comparison again indicate certain but small change in the structure of Brazil's agrifood trade pattern between the first and last year of the period observed. It would again support the argument that the Brazil's agri-food trade has formed by following comparative advantage of specific agri-food sectors.

\section{Stability II (intra-distributional dynamics)}

Using previous analysis of overall specialization pattern, it is possible to gather only some information about the shape of the overall distribution of the BI, LFI and NI indices, but not much can be said as regards the changes in the relative position of any single product. The mobility of products within the distribution was analyzed to investigate intra-distributional dynamics and transitions among the subsequent classes: CdisA (class a), weak CA (class b), medium CA (class c) and strong CA (class d). The scores in Markov transition probability matrices are presented in the Table 6 .

Diagonal elements of the matrix indicate that from one period to the next, the observations of the BI, LFI and NI indices are more persistent for the products revealing CdisA (class a) and strong CA (class d) than for products revealing weak CA (class b) and medium CA (class c). These also mean that the product without initial CA seem to remain to be uncompetitive whilst the product with strong initial CA continue to maintain its competitive position. Above that, in the case of products revealing CdisA, the probability maintaining the same status over the years is very high (BI: 0.98; LFI: 0.96; NI: 0.99). This represents, ceteris paribus, an adverse indication in terms of possible change of Brazil's agri-food RCA pattern towards its more divers' profile.

Products belonging to the central groups (weak CA and medium CA) show very similar (and relatively low) probability to change the status according to BI and LFI. Products revealing medium CA show lower probability $(0.54)$ to maintain the status in comparison to products revealing weak CA (0.77) according to NI.

In general, the probabilities of shifts from less 


\begin{tabular}{|l|c|c|c|c|c|}
\hline \multicolumn{7}{|c|}{ Brazil $\leftrightarrow$ World (BI) } \\
\hline$P_{i j}(-)$ & $i(-)$ & $\mathrm{a}$ & $\mathrm{b}$ & $\mathrm{c}$ & $\mathrm{d}$ \\
\hline$j(-)$ & & & & & \\
\hline $\mathrm{a}$ & & 0.98 & 0.01 & 0.00 & 0.00 \\
\hline $\mathrm{b}$ & & 0.10 & 0.75 & 0.12 & 0.00 \\
\hline $\mathrm{c}$ & & 0.00 & 0.11 & 0.80 & 0.07 \\
\hline $\mathrm{d}$ & & 0.00 & 0.00 & 0.12 & 0.88 \\
\hline
\end{tabular}

\begin{tabular}{|l|c|c|c|c|c|}
\hline \multicolumn{7}{|c|}{ Brazil $\leftrightarrow$ World (LFI) } \\
\hline$P_{i j}(-)$ & $i(-)$ & $\mathrm{a}$ & $\mathrm{b}$ & $\mathrm{c}$ & $\mathrm{d}$ \\
\hline$j(-)$ & & & & & \\
\hline $\mathrm{a}$ & & 0.96 & 0.03 & 0.00 & 0.00 \\
\hline $\mathrm{b}$ & & 0.16 & 0.78 & 0.04 & 0.00 \\
\hline $\mathrm{c}$ & & 0.00 & 0.11 & 0.78 & 0.08 \\
\hline $\mathrm{d}$ & & 0.00 & 0.00 & 0.08 & 0.91 \\
\hline
\end{tabular}

\begin{tabular}{|l|c|c|c|c|c|}
\hline \multicolumn{7}{|c|}{ Brazil $\leftrightarrow$ World (NI) } \\
\hline$P_{i j}(-)$ & $i(-)$ & $\mathrm{a}$ & $\mathrm{b}$ & $\mathrm{c}$ & $\mathrm{d}$ \\
\hline$j(-)$ & & & & & \\
\hline $\mathrm{a}$ & & 0.99 & 0.01 & 0.00 & 0.00 \\
\hline $\mathrm{b}$ & & 0.06 & 0.77 & 0.13 & 0.01 \\
\hline $\mathrm{c}$ & & 0.00 & 0.25 & 0.54 & 0.16 \\
\hline $\mathrm{d}$ & & 0.00 & 0.00 & 0.18 & 0.81 \\
\hline
\end{tabular}

Source: Authors own representation, based on UNCTAD data (SITC, 3-digit level)

Table 6: Markov transition probability matrices for the RCAs indices.

advantageous groups to more advantageous groups are lower in comparisons to shifts from more advantageous groups backwards to less advantageous groups.

The probabilities of closer shifts are higher that the probabilities of longer moves between classes. Even so, the results indicate that there are shifts only between the next groups (lower or upper). Conversely, the probability of the change e.g., from strong $\mathrm{CA}$ to weak $\mathrm{CA}$ is zero and vice versa.

The general degree of mobility was assessed using traces and the determinants of transition matrixes for the whole period as well as in sub-periods (Table 7). In the case of total persistence, the value of M1 would be zero. In the case of total mobility, the M1 would be 1 . For M2, when the values on the main diagonal are close to 1 and those on the off-diagonal small (high persistence), the matrix determinant takes a value close to 1 and the mobility indicator is 0 .

\begin{tabular}{|l|c|c|c|c|c|c|}
\hline \multirow{2}{*}{$\begin{array}{l}\text { RCA } \\
\text { index }\end{array}$} & \multirow{2}{*}{$\begin{array}{c}\text { Mobility } \\
\text { index }\end{array}$} & \multicolumn{6}{|c|}{ Period } \\
\cline { 3 - 7 } & $\mathbf{9 5 - 1 7}$ & $\mathbf{9 5 - 0 0}$ & $\mathbf{0 0 - 0 5}$ & $\mathbf{0 5 - 1 0}$ & $\mathbf{1 0 - 1 7}$ \\
\hline \multirow{2}{*}{ BI } & M1 & 0.20 & 0.32 & 0.27 & 0.17 & 0.10 \\
\cline { 2 - 7 } & M2 & 0.50 & 0.75 & 0.63 & 0.45 & 0.29 \\
\hline \multirow{2}{*}{ LFI } & M1 & 0.19 & 0.29 & 0.25 & 0.13 & 0.15 \\
\cline { 2 - 7 } & M2 & 0.48 & 0.67 & 0.58 & 0.35 & 0.39 \\
\hline \multirow{2}{*}{ NI } & M1 & 0.30 & 0.27 & 0.35 & 0.29 & 0.30 \\
\cline { 2 - 7 } & M2 & 0.72 & 0.64 & 0.80 & 0.72 & 0.80 \\
\hline
\end{tabular}

Source: Authors' calculations based on UNCTAD data (SITC, 3-digit level)

Table 7: Mobility indices of the BI, LFI and NI.
The scores of M1 (BI: 0.20; LFI: 0.19; NI: 0.30) indicate rather persistence than mobility in general (the whole period between 1995 and 2017). For the same period, the M2 scores suggest neither mobility nor persistence (BI: 0.50, LFI: 0.48) or mobility in the case of NI (0.72).

Important insight gives the comparison of scores in specific sub-periods. Scores of both M1 and M2 for BI and LFI are declining thus the persistence is growing. In other words, the probability, that product groups will change its status is getting lower year after year. The NI does not indicate such a change, but it can be caused by the principal properties of the index.

Although the external shape of Brazil's specialization in agri-food trade is slightly increasing (especially in the post-crises period), this suggests that product groups to a greater extent keep their status regarding its class (CdisA, weak CA, medium CA or strong CA).

\section{Conclusion}

From being a net-agricultural importer and food aid recipient as recently as the 1960 s and 1970s, Brazil has actively developed its comparative advantage in agri-food production and trade, has become a global agri-food powerhouse and serious competitor to the global market dominance of the world's leading agricultural exporters. Also, agriculture has become one of the main pillars for the Brazilian economy. The successful story of Brazilian competitive tropical agriculture model attracts attention and intense interest 
from its competitors as well as from other developing countries. Contrary, this "regressive" trade specialization towards both production and export structures strongly oriented to primary and resource-based manufactured goods is currently discussed in terms of potential risks to the Brazilian economy. It also represents clear failure of most of goals of structuralist import substitution industrialization and also (in time period under scrutiny) of neo-developmentalist policies. On the global level, these changes also mean the rise up of Brazil's position and importance regarding provision of the global food security and the environmental sustainability.

Our study has covered the development of Brazilian agri-food sector in last 25 years in order to take a look at comparative advantage in particulars products.

The cross sectoral comparison and revealed CA or CdisA (based on scores of BI, LFI and NI) of specific products is in line with general perception of Brazil as the world's leading exporter especially of soybean and soybean-based products (SITC codes 222, 081), sugarcane-based products (061), unmanufactured tobacco (121), coffee (071), orange juice (059) and meat (011-017). The share of products revealing CA resp. CdisA on Brazil's agri-food export resp. import has increased and it would support the argument that the Brazil's agrifood trade was formed by following comparative advantage of specific agri-food sectors. But it is necessary to take into consideration, that the differences in conditions for agriculture production as well as degree of protectionism and set-ups of trading regimens are affecting the distribution of revealed comparative advantages in relation to main agri-food trading partners of Brazil.

In line with existing empirical literature, the Brazil's revealed comparative advantages in sectors constituting its agri-food trade were assessed two-ways: 1) regarding the external shape of specialization, and 2) regarding the intradistributional dynamics of specific sectors.

The result of the analyses (summary statistics, correlation between indices in time, relative importance of products that reveal $\mathrm{CA}$ or disA in the export and import flows) indicate three specific developmental phases in the overall degree of Brazil's specialization in particular agri-food products (the external shape). There was certain weakening in Brazil's overall degree of specialization at the beginning of the analyzed period, followed by strong specialization tendency since beginning of 2000's when Brazil's agri-food export started to grow very rapidly as an result of the tariff reduction and due to the commodity boom on the world agrarian markets. Also, the development of south-south trade linkage between China and Latin America and especially the boost of Brazil's soya production (and its export to China) intensified the changes; the degree of Brazil's specialization has amplified in the postGreat Recession period.

According to $\mathrm{BI}$ and NI scores, 8 products $(012 ; 017 ; 059 ; 061 ; 071 ; 081 ; 121 ; 222)$ were exhibiting the CA in every year from 1995 to 2017. The comparative (dis)advantage status of only few products have changed: 3 products (bovine meat, 011; meat, ed. offl., dry, slt, smk, 016; maiz, 044) gain CA; 2 products deteriorated (spices, 075; fixed veg. fat, oils, soft, 421) and started to reveal CdiA. Beside these, the changes in scores of LFI indicated some other but minor changes.

This suggests that the change in the external shape of Brazil's specialization in particular agri-food products has following characteristics 1) products that revealed comparative (dis)advantage in 1995 rather continue to maintain its (un)competitive position till 2017, in other words, the structure of Brazil's agri-food trade pattern was rather stable according what products reveal CA or CdisA, 2) some changes occurred in how strong the comparative advantage of each product was and in ranking of specific product groups.

The intra-distributional dynamics was further interrogated using Markov probability matrixes. Products with initial strong CA have maintained its competitive position. Products revealing weak CA or medium CA show high probability to maintain the status (according to BI, LFI and NI). Only exception was indicated by NI in the case of products revealing medium CA and it suggests the same probability to maintain or change the status. If any changes, the probabilities of closer shifts were higher that the probabilities of longer moves between classes. Results indicate that there were shifts only between the next groups (lower or upper). Further, the probabilities of shifts from less advantageous groups to more advantageous groups were lower in comparisons to shifts from more advantageous groups backwards to less advantageous groups. Further insight to intra-distributional dynamics was given by mobility indices. The comparison of scores in specific sub-periods indicates that the probability the product will change its status is getting lower year after year. 
Our analysis shows, that Brazil agri commodity specialization, and agri business competitiveness was consistently strengthening through commodity boom and after its end. This pattern of specialization and export is lasting and robust feature of BRA economy in contrast with neo-developmentalist strategies of presidents da Silva and Rousseff (2003-2016).

This supports the conclusion that although the degree of Brazil's specialization in particular agri-food products has increased, specific product groups to a greater extent keep their status regarding its class (CdisA, weak CA, medium $\mathrm{CA}$ and strong CA) and the shape of Brazil's revealed CA and specialization in particular agri-food products has evolved towards its finite structure (ceteris paribus). It is also important to mention, that while the commodity (China) boom came to end in 2014-2015, even our most recent data do not suggest substantial weakening of this trend of production and trade specialization. This also

Corresponding authors

Ing. Ivo Zdráhal, Ph.D.

Department of Regional and Business Economy Faculty of Regional Development and International Studies, Mendel University in Brno, Zemědělská 1665/1, 61300 Brno, Czech Republic

Phone: +420 545136 409, E-mail: ivo.zdrahal@mendelu.cz

\section{References}

[1] Aiginger, K. (2001) "Specialization of European manufacturing", Austrian Economic Quarterly, Vol. 5, No. 2, pp. 81-92. ISSN 1936-4806.

[2] Amman, E. and Barrientos A. (2016) "Introduction - Is there a Brazilian development 'model'?", Quarterly Review of Economics and Finance, Vol. 62, pp. 7-11. ISSN 1062-9769. DOI 10.1016/j.qref.2016.07.013.

[3] Andrade, D. (2017) "Export or die': the rise of Brazil as an agribusiness powerhouse", Third World Thematics: A TWQ Journal, Vol. 1, No. 5, pp. 653-672. ISSN 2379-9978. DOI 10.1080/23802014.2016.1353889.

[4] Balassa, B. (1965) "Trade Liberalisation and Revealed Comparative Advantage", The Manchester School, Vol. 33, No. 2, pp. 99-123. ISSN 1467-9957. DOI 10.1111/j.1467-9957.1965.tb00050.x.

[5] Ballance, R., Fostner, H. and Murray, T. (1987) "Consistency tests of alternative measures of comparative advantage", The Review of Economics and Statistics, Vol. 69, No. 1, pp. 157-161. ISSN 00346535. DOI 10.2307/1937915.

[6] Ban, C. (2013) "Brazil's liberal neo-developmentalism: New paradigm or edited orthodoxy?", Review of International Political Economy, Vol. 20, No. 2, pp. 298-331. ISSN 1466-4526. DOI 10.1080/09692290.2012.660183.

[7] Belova, A. V., Smutka, L. and Rosochatecká, E. (2012) "World chicken meat market - its development and current status", Acta univ. agric. et silvic. Mendel. Brun., Vol. 60, No. 4, pp. 15-30. ISSN 2464-8310. DOI 10.11118/actaun201260040015.

[8] Benešová, I., Smutka, L. and Laputková, A. (2018) "Specifics of the Mutual Trade of the Post-Soviet Countrie", Entrepreneurial Business and Economics Review, Vol. 7, No. 1. E-ISSN 2353-8821, ISSN 2353-883X. DOI 10.15678/EBER.2019.070102. 
[9] Bilan Y., Mishchuk, H., Roshchyk, I. and Kmecova I. (2020) "Analysis of Intellectual Potential and its Impact on the Social and Economic Development of European Countries", Journal of Competitiveness, Vol. 1, pp. 22-38. E-ISSN 1804-1728, ISSN 1804-171X. DOI 10.7441/joc.2020.01.02.

[10] Bojanic, A. H. (2017) "The Rapid Agricultural Development of Brazil in the Last 20 Years", EuroChoices, Vol. 16, No. 1, pp. 5-10. ISSN 1746-962X. DOI 10.1111/1746-692X.12143.

[11] Bowen, H. (1983) "On the Theoretical Interpretation of Indices of Trade Intensity and Revealed Comparative Advantage", Review of World Economics, Vol. 119, No. 3, pp. 464-472. ISSN 1610-2886.

[12] Brasili, A., Epifani, P. and Helg, R. (2000) "On the dynamics of trade patterns", De Economist, Vol. 148, No. 2, pp. 233-258. ISSN 1572-9982. DOI 10.1023/A:1004065229330.

[13] Bresser-Pereira, L. C. (2009) "From Old to New Developmentalism in Latin America", in J. A. Ocampo and J. Ros, (eds.), The Oxford Handbook of Latin America Economics, Oxford, Oxford University Press. ISBN-13 978-0199571048.

[14] Brodzicki, T. and Kwiatkowski, J. (2018) "An Empirical Investigation into the Role of Technology Gap in the Trade Relations of the EU Member States", Entrepreneurial Business and Economics Review, Vol. 6, No. 2, pp. 111-135. E-ISSN 2353-8821, ISSN 2353-883X. DOI 10.15678/EBER.2018.060206.

[15] Brodzicki, T., Márquez-Ramos, L. and Umiński, S. (2018) "The Investigation into Determinants of Regional Exports Base: Panel Analysis for Spanish and Polish Regions", Entrepreneurial Business and Economics Review, Vol. 6, No. 1, pp. 135-151. E-ISSN 2353-8821, ISSN 2353-883X. DOI 10.15678/EBER.2018.060108.

[16] Bureau, J., Guimbard, H. and Jean S. (2019) “Agriculture Trade Liberalisation in the $21^{\text {st }}$ century: Has It Done the Business?”, Journal of Agricultural Economics, Vol. 70, No. 1, pp. 3-25. ISSN 1477-9552. DOI 10.1111/1477-9552.12281.

[17] Chaddad, F., R. and Jank, M. S. (2006) "The Evolution of Agricultural Policies and Agribusiness Development in Brazil", Choices: The Magazine of Food, Farm, and Resource Issues, Vol. 21, No. 2, pp. 85-90. DOI 10.22004/ag.econ.94415.

[18] Contini, E., Gasques, J. G., Alves, E. and Bastos, E. T. (2010) "Dynamism of Brazilian agriculture", Revista de Política Agrícola, Vol. 19 (special issue), pp. 42-63. ISSN 2317-224X.

[19] Cypher, J. M. (2014) "Brazil: Neoliberal Restructuring or Rejuvenation of the Developmental State?", In Global Economic Crisis and the Politics of Diversity. London, Palgrave Macmillan. ISBN-13: 978-1349451319.

[20] Dalum, B., Laursen, K. and Villumsen, G. (1998) "Structural change in OECD export specialization patterns: de-specialization and stickiness", International Review of Applied Economics, Vol. 12, No. 3, pp. 423-443. ISSN 1465-3486. DOI 10.1080/02692179800000017.

[21] De Benedictis, L. and Tamberi, M. (2004) "Overall Specialization Empirics: Techniques and Applications", Open Economies Review, Vol. 15, No. 4, pp. 323-346. ISSN 1573-708X. DOI 10.1023/B:OPEN.0000048522.97418.99.

[22] de Paula, M. F., Angelo, H., Santos, A. J., de Almeida, A. N., de Andrade Vasconcelos, P. G., Schwans, A., Miguel, E. P. and Ribas, A. J. F. (2018) "Competitiveness of Brazilian soybean exports", African Journal of Agricultural Research, Vol. 13, No. 44, pp. 2499-2509. ISSN 1991-637X. DOI 10.5897/AJAR2018.13398.

[23] Directorate General for International Policies (2014) "Agriculture in Brazil and Relations with the EU", European Union, 2014. [Online]. Available: https://1url.cz/JzNoe [Accessed: 20 Oct. 2019].

[24] EIU - Economic Inteligence Unite (2010) "The Global power of Brazilian agribusiness", [Online]. Available: http://6b.cz/nurO [Accessed: 18 Oct. 2019]. 
[25] Ferto, I. and Hubbard, L. J. (2003) "Revealed Comparative Advantage and Competitiveness in Hungarian Agri-Food Sectors", The World Economy, Vol. 26, No. 2, pp. 247-259. ISSN 1467-9701. DOI 10.1111/1467-9701.00520.

[26] Fujita, M., Krugman, P. and Venables, A. (1999) “The Spatial Economy: Cities, Regions, and International Trade”, Cambridge, MA: MIT Press. ISBN-13: 978-0262561471.

[27] Grossman, G. and Helpman, E. (1991) “Innovation and Growth in the Global Economy”, Cambridge, MA: MIT Press. ISBN-13 978-0262570978.

[28] Hinloopen, J. and van Marrewijk, C. (2001) "On the Empirical Distribution of the Balassa Index", Review of World Economics, Vol. 137, No. 1, pp. 1-35. ISSN 1610-2886. DOI 10.1007/BF02707598.

[29] Hoang, V. V. (2019) "Investigating the evolution of agricultural trade specialization in transition economies: A case study from Vietnam", The International Trade Journal, Vol. 33, No. 4, pp. 361-378. ISSN 1521-0545. DOI 10.1080/08853908.2018.1543622.

[30] Hoen, A. and Oosterhaven, J. (2006) "On the measurement of competetive Advantage", The Annals of Regional Science, Vol. 40, No. 3, pp. 677-691. ISSN 1432-0592. DOI 10.1007/s00168-006-0076-4.

[31] Hopewell, K. (2016) "The accidental agro-power: constructing comparative advantage in Brazil", New Political Economy, Vol. 21, No. 6, pp. 536-554. ISSN 1469-9923. DOI 10.1080/13563467.2016.1161014.

[32] Hubbard, C., Alvim, A. M. and Garrod, G. (2017) "Brazilian Agriculture as a Global Player", EuroChoices, Vol. 16, No. 1, pp. 3-4. ISSN 1746-962X. DOI 10.1111/1746-692X.12142.

[33] Hubbard, C., Alvim, A. M., Mattos, E. J. and Hubbard, L. (2017) "Agri-food Trade Between Brazil and the EU”, EuroChoices, Vol. 16, No. 1, pp. 11-16. ISSN 1746-962X. DOI 10.1111/1746-692X.12144.

[34] Im, J. and Hong, C. (2015) "Brazil's Agricultural Situation and Export Competitiveness of Soybean in the World and Korean Market", J. Korean Soc. Int. Agric., Vol. 27, No. 5, pp. 600-608. ISSN 2287-8165. DOI 10.12719/KSIA.2015.27.5.600.

[35] Kostiukevych, R., Mishchuk, H., Zhidebekkyzy, A., Nakonieczny, J. and Akimov, O. (2020) "The impact of European integration processes on the investment potential and institutional maturity of rural communities", Economics and Sociology, Vol. 13, No. 3, pp. 46-63. E-ISSN 2306-3459, ISSN 2071-789X. DOI 10.14254/2071-789X.2020/13-3/3.

[36] Kostoska, O. and Hristoski, I. (2018) "Trade dynamics, revealed comparative advantage, and international competitiveness: Evidence from Macedonia", Economic Annals, Vol. 63, No. 218, pp. 23-58. ISSN 0013-3264. DOI 10.2298/EKA1818023K.

[37] Krugman, P. (1987) "The narrow mowing band, the Dutch disease, and the competitive consequences of Mrs. Thatcher: notes on trade in the presence of dynamic scale economies", Journal of Development Economics, Vol. 27, No. 1-2, pp. 41-55. ISSN 0304-3878. DOI 10.1016/0304-3878(87)90005-8.

[38] Krugman, P. (1991) “Geography and Trade”, Cambridge, MA: MIT Press. ISBN 0-262-11159-4.

[39] Lafay, G. (1992) “The measurement of revealed comparative advantages” In: DAGENAIS, M. G. and MUET, P.-A. (eds.) International Trade Modelling. London: Chapman \& Hall. ISBN 0-412-45000-3.

[40] Leromain, E. and Orefice, G. (2014) "New revealed comparative advantage index: Dataset and empirical distribution", International Economics, Vol. 139, pp. 48-70. ISSN 2110-7017. DOI 10.1016/j.inteco.2014.03.003.

[41] Lisin, E., Rogalev, N. and Okley, P. (2019) "The impact model of the production capacities structure of the energy system and the regional energy security", Terra Economicus, Vol. 17, No. 2, pp. 96-111. E-ISSN 2410-4531, ISSN 2073-6606. DOI 10.23683/2073-6606-2019-17-2-96-111.

[42] Lucas, R. (1988) "On the mechanics of economic development", Journal of Monetary Economics, Vol. 22, No. 1, pp. 3-42. ISSN 0304-3932. DOI 10.1016/0304-3932(88)90168-7. 
[43] Maciejewski, M. (2019) "The Similarity of the Demand Structure as a Determinant of the Commodity Structure of Bilateral Trade in the European Union Countries", Entrepreneurial Business and Economics Review, Vol. 7, No. 2, pp. 249-262. DOI 10.15678/EBER.2019.070214.

[44] Maciel, J. (2018) "Policy Tools to Transform Agriculture: the Brazil Experience", [Online]. Available: https://1url.cz/LzehZ [Accessed: 10 Dec. 2019].

[45] Maitah, M., Řezbová, H., Smutka, L. and Tomšík, K. (2016) “European Sugar Production and its Control in the World Market", Sugar Tech, Vol. 18, No. 3, pp. 236-241. ISSN 0974-0740. DOI 10.1007/s12355-016-0439-9.

[46] Martha, G. B., Alves, E., Contini, E., Ramos, S. Y. (2010) "The development of Brazilian agriculture and future challenges", Revista de Política Agrícola, Vol. 19 (special issue), pp. 91-104. ISSN 2317-224X.

[47] Milovanovic, V. and Smutka, L. (2017) “Asian countries in the global rice market”, Acta Universitatis Agriculturaevet Silviculturae Mendelianae Brunensis, Vol. 65, No. 2, pp. 679-688. ISSN 2464-8310. DOI 10.11118/actaun201765020679.

[48] Morais, L., and Saad-Filho, A. (2012) "Neo-developmentalism and the challenges of economic policy-making under Dilma Rousseff”, Critical Sociology, Vol. 38, No. 6, pp. 789-798. ISSN 1569-1632. DOI 10.1177/0896920512441635.

[49] Moreddu, C., Contini, E. and Ávila, F. (2017) "Challenges for the Brazilian Agricultural Innovation System”, EuroChoices, Vol. 16, No. 1, pp. 26-31. ISSN 1746-692X. DOI 10.1111/1746-692X.12147.

[50] Mueller, B. and Mueller, C. (2016) "The Political Economy of the Brazilian Model of Agricultural Development: Institutions Versus Sectoral Policy”, Quarterly Review of Economics and Finance, Vol. 62, pp. 12-20. ISSN 1062-9769. DOI 10.1016/j.qref.2016.07.012.

[51] Nassif, A. and Castilho, M. R. (2020) "Trade patterns in a globalised world: Brazil as a case of regressive specialisation", Cambridge Journal of Economics, Vol. 44, No. 2, pp. 671-701. ISSN 0309-166X. DOI 10.1093/cje/bez069.

[52] Nazarczuk, J. M., Umiński, S. and Gawlikowska-Hueckel, K. (2018) "The Role of Specialization in the Export Success of Polish Counties in 2004-2015“, Entrepreneurial Business and Economics Review, Vol. 6, No. 2, pp. 91-109. ISSN 2353-8821. DOI 10.15678/EBER.2018.060205.

[53] Pereira, P. A. A., Martha, G. B., Santana, C. A. and Alves, E. (2012) “The development of Brazilian agriculture: future technological challenges and opportunities”, Agriculture \& Food Security, Vol. 1, No. 4., pp. 1-12. ISSN 2048-7010. DOI 10.1186/2048-7010-1-4.

[54] Proudman, J., and Redding S. (2000) "Evolving patterns of international trade", Review of International Economics, Vol. 8, No. 3, pp. 373-396. ISSN 1467-9396. DOI 10.1111/1467-9396.00229.

[55] Quah, D. T. (1996) "Empirics for economic growth and convergence”, European Economic Review, Vol. 90, No. 6, pp. 1353-1375. ISSN 0014-2921. DOI 10.1016/0014-2921(95)00051-8.

[56] Redding, S. (1999) "Dynamic Comparative Advantage and the Welfare Effects of Trade", Oxford Economic Papers, Vol. 51, Vol. 1, pp. 15-39. ISSN 1464-3812.

[57] Sanidas, E. and Shin, Y. (2010) "Comparison of revealed comparative advantage indices with application to trade tendencies of East Asian countries". [Online]. Available: https://1url.cz/NMgPH [Accessed: 20 Oct. 2019].

[58] Siqueira, K., Carvalho, G. and Pinha, L. C. (2011) "Revealed comparative advantage and the context of Brazil in international dairy market”, Economics Bulletin, AccessEcon, Vol. 31, No. 1, pp. 1-7. ISSN 1545-2921.

[59] Smutka, L., Maitah, M. and Svatoš, M. (2018) "Changes in the Czech agrarian foreign trade competitiveness - different groups of partners' specifics”, Agric. Econ. - Czech, Vol. 64, No. 9, pp. 399-411. ISSN 1805-9295. DOI 10.17221/399/2016-AGRICECON. 
[60] Smutka, L., Rovný, P. and Palkovič, J. (2020) "Sugar prices development: The relation among selected commodity stocks exchange", Journal of International Studies, Vol. 13, No. 2, pp. 310-328. E-ISSN 2306-3483, ISSN 2071-8330. DOI 10.14254/2071-8330.2020/13-2/21.

[61] Sterns, J. A., and Spreen, T. H. (2010) "Evaluating Sustainable Competitive Advantages in Brazilian and U.S. Processed Citrus Supply Chains: An Application of Porter's Diamond Framework", International Journal on Food System Dynamics, Vol. 1, No. 2, pp. 1-9. ISSN 1869-6945.

[62] Svatoš, M. and Smutka, L. (2010) "Development of agricultural foreign trade in the countries of central Europe“, Agric. Econ. - Czech, Vol. 56, No. 4, pp. 163-175. ISSN 1805-9295. DOI 10.17221/22/2010-AGRICECON.

[63] Torok, A., Mizik, T., and Jambor, A. (2018) "The Competitiveness of Global Coffee Trade", International Journal of Economics and Financial Issues, Vol. 8, No. 5, pp. 1-6. ISSN 2146-4138. DOI 10.32479/ijefi.6692.

[64] Vollrath, T. (1991) "A Theoretical Evaluation of Alternative Trade Intensity Measures of Revealed Comparative Advantage", Review of World Economics, Vol. 127, No. 2, pp. 263-279. ISSN 1610-2886. DOI 10.1007/BF02707986.

[65] Yu, R., Cai, J. and Leung, P. (2009) "The Normalized Revealed Comparative Advantage Index", The annals of regional Science, Vol. 43, No. 1, pp. 267-282. ISSN 1432-0592. DOI 10.1007/s00168-008-0213-3.

[66] Zaghini, A. (2003) "Trade advantages and specialization dynamics in acceding countries", Working paper № 249, Frankfurt am Main, Germany: European Central Bank, pp. 4-15.

[67] Zaghini, A. (2005) "Evolution of trade patterns in the new EU member states", Economics of Transition, Vol. 13, No. 4, pp. 629-658. ISSN 2577-6983. DOI 10.1111/j.0967-0750.2005.00235.x.

[68] Zdráhal, I., Daňková, B., Hrabálek, M., Juráňová, L. and Vašíčková, D. (2019) “Agri-food Trade Patterns of Brazil: the Role of European Union and China?", Proceedings of the $28^{\text {th }}$ International Scientific Conference Agrarian Perspectives XXVIII. Prague: Czech University of Life Sciences Prague, 2019, pp. 371-378. ISBN 978-80-213-2973-7. 


\section{Appendix}

\begin{tabular}{|c|c|c|c|}
\hline 001 & Live animals & 057 & Fruit, nuts excl. oil nuts \\
\hline 011 & Bovine meat & 058 & Fruit, preserved, prepared \\
\hline 012 & Other meat, other offal & 059 & Fruit, vegetable juices \\
\hline 016 & Meat, ed. offl., dry, slt, smk & 061 & Sugars, molasses, honey \\
\hline 017 & Meat, offl. Prdd, nes & 062 & Sugar, confectionery \\
\hline 022 & Milk and cream & 071 & Coffee, coffee substitutes \\
\hline 023 & Butter, other fat of milk & 072 & Cocoa \\
\hline 024 & Cheese and curd & 073 & Chocolate, oth. cocoa prep. \\
\hline 025 & Eggs, birds, yolks, albumin & 074 & Tea and mate \\
\hline 034 & Fish, fresh, chilled, frozn & 075 & Spices \\
\hline 035 & Fish, dried, salted, smoked & 081 & Animal feed stuff \\
\hline 036 & Crustaceans, Molluscs & 091 & Margarine and shorten \\
\hline 037 & Fish etc. prepd, prsvd. nes & 098 & Edible prod. prepetns, nes \\
\hline 041 & Wheat, Meslin, Unmilled & 111 & Non-alcohol. beverage \\
\hline 042 & Rice & 112 & Alcoholic Beverages \\
\hline 043 & Barley, unmilled & 121 & Tobacco, unmanufactured \\
\hline 044 & Maize unmilled & 122 & Tobacco, manufactured \\
\hline 045 & Other cereals, unmilled & 222 & Oil seeds and oleaginous fruits (excl. flour) \\
\hline 046 & Meal, Flour of wheat, msln & 223 & Oil seeds, oleaginous fruits (incl. flour, n.e.s.) \\
\hline 047 & Other cereal meal, flours & 411 & Animal oils and fats \\
\hline 048 & Cereal preparations & 421 & Fixed veg. fat, oils, soft \\
\hline 054 & Vegetables & 422 & Fixed veg. fat, oils, other \\
\hline 056 & Vegetables, prpd, prsvd, nes & 431 & Animal, veg. Fats, oils, nes. \\
\hline
\end{tabular}

Source: SITC rev.3

Table A1: Sectors and their numeric designations (SITC rev.3, 3-digit code). 


\begin{tabular}{|c|c|c|c|c|c|c|c|c|c|c|c|c|c|}
\hline SITC & MCS & LAC & EU28 & USA & China & RoW & SITC & MCS & LAC & EU28 & USA & China & RoW \\
\hline 001 & 5.21 & 0.54 & -0.05 & -0.16 & 0.00 & 0.03 & 057 & -2.01 & -6.98 & -0.85 & -0.11 & -0.05 & -0.58 \\
\hline 011 & 3.78 & 5.32 & 0.56 & 0.04 & 0.07 & 0.69 & 058 & -0.02 & -1.13 & -0.08 & 0.04 & -0.05 & -0.02 \\
\hline 012 & 6.08 & 5.22 & 0.31 & 0.04 & 0.21 & 1.63 & 059 & 0.15 & 0.17 & 1.54 & 3.25 & 0.03 & 0.03 \\
\hline 016 & 0.01 & 0.01 & 0.41 & 0.00 & n.d. & 0.01 & 061 & 4.86 & 2.86 & 0.37 & 0.67 & 0.33 & 2.22 \\
\hline 017 & 0.50 & 1.48 & 0.91 & 1.79 & 0.00 & 0.06 & 062 & 0.72 & -0.15 & -0.07 & 0.20 & -0.04 & 0.00 \\
\hline 022 & -1.98 & -0.28 & -0.11 & -0.50 & 0.00 & -0.05 & 071 & 2.41 & 3.03 & 3.20 & 9.39 & 0.00 & 0.20 \\
\hline 023 & -0.09 & 0.01 & -0.03 & 0.00 & n.d. & -0.01 & 072 & 1.81 & 0.58 & -0.14 & 0.54 & -0.05 & -0.82 \\
\hline 024 & -1.03 & 0.07 & -0.24 & -0.03 & 0.00 & -0.01 & 073 & 0.52 & 0.12 & -0.41 & -0.59 & -0.01 & -0.10 \\
\hline 025 & 0.51 & 0.10 & -0.03 & -0.78 & n.d. & 0.01 & 074 & 1.15 & 0.04 & -0.03 & -0.07 & -0.01 & -0.01 \\
\hline 034 & -1.34 & -17.31 & -0.60 & 0.18 & -1.43 & -0.79 & 075 & 0.18 & 0.44 & 0.11 & 0.65 & -0.03 & -0.15 \\
\hline 035 & 0.00 & -0.05 & -0.38 & 0.00 & -0.64 & -0.91 & 081 & 1.28 & 3.45 & 3.16 & -1.77 & -0.76 & 0.38 \\
\hline 036 & -0.04 & -0.27 & -0.01 & 0.36 & -0.08 & 0.00 & 091 & 0.03 & 0.07 & -0.05 & -0.10 & n.d. & -0.05 \\
\hline 037 & 0.17 & -1.56 & -0.06 & 0.04 & -0.03 & -0.12 & 098 & 1.72 & 2.02 & -1.42 & -4.01 & -0.24 & -0.18 \\
\hline 041 & -12.32 & 0.15 & 0.01 & -10.68 & 0.00 & -0.20 & 111 & 0.07 & 0.04 & -0.52 & 0.01 & 0.00 & -0.05 \\
\hline 042 & -2.31 & 2.08 & -0.03 & -0.06 & n.d. & 0.01 & 112 & 0.55 & -4.16 & -2.85 & -0.54 & 0.00 & -0.06 \\
\hline 043 & -1.10 & 0.00 & -0.10 & 0.00 & 0.00 & 0.00 & 121 & 1.15 & 0.58 & 1.10 & 2.26 & 0.14 & 0.03 \\
\hline 044 & -0.40 & 5.66 & 0.39 & 0.65 & 0.01 & 0.82 & 122 & 0.60 & 0.09 & -0.05 & -0.04 & 0.00 & -0.01 \\
\hline 045 & -0.11 & -0.11 & 0.00 & -0.04 & -0.01 & -0.03 & 222 & -0.89 & 0.83 & 2.77 & 0.99 & 5.19 & 0.62 \\
\hline 046 & -1.61 & 0.00 & -0.02 & -0.01 & 0.00 & -0.01 & 223 & -0.05 & -0.24 & -0.03 & -0.01 & -0.01 & -0.01 \\
\hline 047 & 0.01 & 0.02 & 0.00 & 0.00 & 0.00 & 0.01 & 411 & -0.21 & -0.16 & -0.03 & -0.04 & -0.02 & -0.02 \\
\hline 048 & -3.33 & 0.25 & -1.44 & -0.20 & -0.01 & -0.05 & 421 & -0.22 & 1.68 & -2.76 & -0.02 & 0.25 & 0.17 \\
\hline 054 & -2.44 & -1.71 & -0.73 & -0.51 & -2.18 & -0.13 & 422 & 0.01 & -1.33 & 0.00 & 0.00 & 0.00 & -2.01 \\
\hline 056 & -2.06 & -1.72 & -1.68 & -0.72 & -0.56 & -0.12 & 431 & 0.09 & 0.25 & -0.04 & -0.09 & -0.01 & -0.42 \\
\hline
\end{tabular}

Note: grey colour - sectors revealing CA (LFI scores higher than 0.1); MCS - MERCOSUR, LAC - states of Latin America and the

Caribbean (excl. MERCOSUR), RoW - rest of the World (excl. MCS, LAC, EU28, USA and China)

Source: Authors' calculations based on UNCTAD data (SITC, 3-digit level)

Table A2: Revealed comparative advantage of Brazil with respect to main trade partners (mean of LFI scores for specific sectors between 2010 and 2017).

\begin{tabular}{|c|c|c|c|c|c|c|c|c|c|c|c|c|}
\hline & 1995 & 1997 & 1999 & 2001 & 2003 & 2005 & 2007 & 2009 & 2011 & 2013 & 2015 & 2017 \\
\hline & \multicolumn{12}{|c|}{ BI } \\
\hline average & 0.88 & 0.79 & 0.90 & 0.87 & 0.87 & 0.86 & 0.93 & 0.85 & 0.81 & 0.79 & 0.81 & 0.79 \\
\hline stand dev. & 1.59 & 1.43 & 1.63 & 1.44 & 1.42 & 1.48 & 1.43 & 1.43 & 1.35 & 1.34 & 1.35 & 1.42 \\
\hline median & 0.10 & 0.13 & 0.13 & 0.12 & 0.15 & 0.16 & 0.17 & 0.15 & 0.16 & 0.14 & 0.16 & 0.11 \\
\hline kurt & 4.36 & 3.57 & 3.84 & 2.81 & 2.60 & 3.33 & 1.93 & 4.15 & 4.24 & 3.50 & 4.13 & 6.42 \\
\hline skew & 2.26 & 2.18 & 2.19 & 1.98 & 1.91 & 2.06 & 1.73 & 2.15 & 2.16 & 2.05 & 2.11 & 2.50 \\
\hline $\min$. & 0.00 & 0.00 & 0.00 & 0.00 & 0.00 & 0.00 & 0.00 & 0.00 & 0.00 & 0.00 & 0.00 & 0.00 \\
\hline \multirow[t]{2}{*}{ max. } & 6.57 & 5.27 & 6.05 & 5.12 & 5.48 & 5.59 & 5.17 & 5.89 & 5.77 & 5.07 & 5.86 & 6.35 \\
\hline & \multicolumn{12}{|c|}{ LFI } \\
\hline average & 0.00 & 0.00 & 0.00 & 0.00 & 0.00 & 0.00 & 0.00 & 0.00 & 0.00 & 0.00 & 0.00 & 0.00 \\
\hline stand dev. & 2.56 & 2.14 & 2.12 & 1.66 & 1.47 & 0.98 & 1.21 & 1.20 & 1.25 & 1.39 & 1.19 & 1.30 \\
\hline median & -0.20 & -0.16 & -0.13 & -0.04 & -0.04 & -0.05 & -0.06 & -0.07 & -0.09 & -0.08 & -0.09 & -0.10 \\
\hline kurt & 5.82 & 4.28 & 5.22 & 9.19 & 11.89 & 4.26 & 7.24 & 4.92 & 4.75 & 7.62 & 9.69 & 13.10 \\
\hline skew & 0.12 & 0.92 & -0.24 & -1.38 & -2.05 & 0.11 & -0.85 & 1.01 & 1.23 & 1.17 & 2.15 & 2.85 \\
\hline $\min$. & -9.60 & -6.42 & -8.10 & -7.59 & -7.15 & -3.48 & -5.14 & -3.63 & -3.51 & -4.41 & -2.61 & -2.30 \\
\hline \multirow[t]{2}{*}{ max. } & 7.83 & 7.41 & 6.28 & 3.84 & 3.25 & 2.63 & 3.13 & 4.33 & 4.29 & 5.80 & 5.56 & 6.51 \\
\hline & \multicolumn{12}{|c|}{$\mathbf{N}$} \\
\hline average & 0.00 & 0.00 & 0.00 & 0.00 & 0.00 & 0.00 & 0.00 & 0.00 & 0.00 & 0.00 & 0.00 & 0.00 \\
\hline stand dev. & 11.98 & 14.34 & 12.64 & 14.12 & 15.31 & 17.94 & 17.10 & 21.69 & 24.09 & 25.31 & 24.46 & 26.73 \\
\hline median & -1.73 & -2.09 & -1.59 & -1.84 & -2.01 & -2.38 & -2.49 & -2.58 & -2.98 & -3.39 & -2.93 & -3.46 \\
\hline kurt & 4.66 & 4.94 & 3.83 & 3.62 & 5.84 & 3.49 & 2.46 & 7.40 & 7.57 & 13.03 & 16.25 & 18.63 \\
\hline skew & 2.09 & 2.15 & 1.82 & 1.71 & 1.97 & 1.70 & 1.42 & 2.38 & 2.51 & 3.08 & 3.40 & 3.78 \\
\hline $\min$. & -15.87 & -19.77 & -20.19 & -23.60 & -26.26 & -29.17 & -30.02 & -29.23 & -30.04 & -30.81 & -33.13 & -33.83 \\
\hline max. & 43.91 & 52.85 & 45.90 & 49.57 & 64.15 & 64.45 & 57.19 & 90.69 & 92.49 & 125.83 & 129.02 & 144.69 \\
\hline
\end{tabular}

Source: Authors' calculations based on UNCTAD data (SITC, 3-digit level)

Table A3: Summary statistics of BI, LFI and NI (selected years). 